decision making. However, our members have expressed anxiety as to what may happen if problems arise in a preliminary examination that might lead to at least a need for legal representation or even claims for compensation.

In order to clarify this matter, I have been in touch with both the Lord Chancellor's Department and the Mental Health and Community Care Division of the Department of Health. I have now been informed that the Departments' solicitors view is that, as members of the tribunal, psychiatrists would be carrying out statutory functions under the Mental Health Act 1983 and that it would be unreasonable for them to be expected to incur any financial liability that may arise. As the Department of Health pays remuneration to members of the MHRT, the Department of Health would bear the cost of any successful claim made for damages.

It is also pointed out that the Mental Health Review Tribunal is established under the Mental Health Act 1983 and Section 139 of the Act provides some protection for persons carrying out functions under the Act. No civll proceedings can be brought against any person without the leave of the High Court, who would have to confirm the act was done in bad faith or without reasonable care.

\section{J. J. BRADLEY}

The Medical Protection Society, 50 Hallam Street, London WIN 6DE

\section{Code of Practice; Section 2 or Section 4 ?}

Sir: The Code of Practice dictates that patients should be assessed for Section 2 wherever possible rather than Section 4. Under the provisions of the Mental Health Act (Scotland) 1984 such a practice is legally impossible. What then is true good practice? I would argue that the Scottish Act has it about right. A patient presenting acutely in a state which requires admission to a mental hospital should be admitted with minimum infringement of rights. Section 2 is, to all intents and purposes (electroconvulsive therapy excluded), a treatment order and such detention should not be embarked on lightly. The Code of Practice, however, interpreted by purchasing authorities and social services seems to demand that senior psychiatrists attend patients at unearthly hours of the night with only two options: release them or detain them under Section 2 which, of course, permits the most junior on call doctor to impose any medication she sees fit. If this is good practice, what is bad?

'Real' good practice dictates that a patient should be addressed for detention under Section 2 by a consultant or equivalent who is functioning on all cylinders which few of us are when we attend a police station at 3 or 4 am. And even if our decision making is reasonable at these hours, what effect does sleep deprivation have on the quality of our decision making in out-patient clinics, ward rounds, and domicliary visits conducted after such an assessment in the early hours of the morning?

I would argue that Section 2 assessments at unsocial hours should be the rarity rather than the norm. We do not after all convene Mental Health Review Tribunals at 3 am immediately to hear appeals against detention!

D. R. DAVIES

Rydon House, Cheddon Road, Taunton TA2 7AZ

\section{Whose journal is it anyway?}

Sir: Samuel Stein \& Rex Haigh (Psychiatric Bulletin. February 1996, 20, 115) pose the question, "how many would stop buying the Journal if it were purchased separately from membership subscription. given the discrepancy between what College members are interested in and what is published?" I would be one such member.

Another interesting analysis would be the percentages of mental health budgets that are spent on sub-specialties compared to general psychiatry.

\section{ROBERT MELLR}

Department of Child and Family Psychiatry. Southmead Hospital, Monks Park Avenue, Bristol BS10 5NB

Sir: Stein \& Haigh (Psychiatric Bulletin. February 1996, 20, 115) show that the British Journal of Psychiatry published disproportionately few articles in specialisms such as psychotherapy and child psychiatry. Their data confirmed what has been my impression over the years.

However, an addendum to their findings is that the book review section has a very different pattern, with a surprisingly high proportion of psychotherapy evident. Takdng the last six months' sample, of the total books reviewed, I calculate that $33 \%$ are psychotherapy or related subjects, $13 \%$ child and adolescent psychiatry and all other subjects total $54 \%$.

Varied conclusions may be developed from this, but one might be: an academic journal doth not a College make.

Nick CHILD

Child and Family Clinics, Atrbles Road Centre, Motherwell ML1 2TJ 